\title{
Sobre a sustentabilidade como fantasia liberal- capitalista: do tampão verde à ecologia sem natureza
}

\section{About sustainability as a liberal-capitalist fantasy: from the green plug towards the ecology without nature}

\author{
José Luiz Aidar Prado \\ visibilidade em revistas". \\ <aidarprado@gmail.com> \\ Vinicius Prates \\ Doutor pela PUC-SP, jornalista e professor do Mackenzie e da Unip. \\ <viniciusprates.vp@gmail.com>
}

Professor doutor do Programa de Estudos Pós-graduados em Comunicação e Semiótica da PUC-SP; editor da revista Galaxia; autor de "Convocações biopolíticas dos dispositivos comunicacionais" e coordenador e organizador da hipermídia "Regime de

\section{RESUMO}

O objetivo desta pesquisa é mapear os modos pelos quais os dispositivos midiáticos especializados em economia e negócios lidam com a tensão entre o discurso liberal-capitalista, que embasa seus contratos de comunicação, e a crise ambiental. A metodologia é a análise discursiva ancorada em Laclau e e Žižek. Para isso foram analisados 629 textos sobre meio ambiente publicados durante um ano nas revistas Exame, IstoÉ Dinheiro e Época Negócios. Foram mapeados os pontos nodais e examinadas as estratégias discursivas que costuram os discursos a partir destes pontos. A análise indicou que o discurso da sustentabilidade corporativa tornou-se a fantasia ideológica que ancora o capitalismo hegemônico; os enunciadores tamponam semioticamente o furo da crise ambiental, erigindo sobre ele os sentidos da sustentabilidade. Dessa forma, os antagonismos ecologistas que poderiam ser ameaças ao contrato, não apenas são absorvidos, como passam a ser o ponto nodal da ideologia neocapitalista, com a promessa de que o crescimento econômico aponte a um futuro verde e limpo.

Palavras-chave: Sustentabilidade. Revistas de negócios. Comunicação.

\section{ABSTRACT}

This research examines the ways through which mediatic devices specialized in economics and business deal with the tension between the liberal capitalist discourse, which underpins its communication contracts, and the environmental crisis. To this end, 629 texts on the theme environment published over a 12-month period in the magazines Exame, IstoÉ Dinheiro and Época Negócios were analyzed. The research revealed that the discourse on corporate sustainability has become the ideological fantasy that supports hegemonic capitalism. Pundits are putting a semiotic cork on news about the environmental crisis, erecting upon it overtones of sustainability. Thus, ecologist antagonisms that could represent threats to the contract are not only absorbed but also become the nodal point of neo-capitalist ideology, with the promise that economic growth points to a green and clean future. The discourse theory employed in this analysis was based on Laclau, Mouffe and Žižek.

Keywords: Sustainability. Business magazines. Comunication. 
A tematização do meio ambiente em crise há muito tempo não é exclusividade da atuação de ecologistas militantes de organizações não governamentais. Além de entrar na agenda dos governos, os enunciados ambientalistas se integraram de forma central nos discursos contemporâneos que euforizam as grandes empresas e o capital globalizado. Os analistas simbólicos do liberal-capitalismo vêm enfrentando a tensão entre, por um lado, a manutenção do discurso desenvolvimentista e, por outro, a proposição de enunciados que apontam a degradação ambiental provocada pelo sistema de produção e consumo. Buscando investigar as maneiras pelas quais a mídia especializada em economia e negócios administra esta tensão, investigamos as três mais influentes revistas do gênero no Brasil: Exame, IstoÉ Dinheiro e Época Negócios. Foram pesquisadas publicações de 2010, sendo 12 números de Negócios, 50 de Dinheiro e 24 de Exame, nos quais encontramos 629 textos que trataram de meio ambiente.

As revistas de economia e negócios criam seus contratos de comunicação com base no discurso do liberal-capitalismo em sua versão contemporânea. De acordo com Foucault (2008, p. 203), este é o discurso que traduz todas as "unidades de base" da sociedade para a"forma empresa", ou seja, promove uma generalização dos processos de gestão e do cálculo administrativo, o que de fato constitui o princípio da "biopolítica". Os veículos especializados oferecem, nessa direção, mais do que informações econômicas: apresentam mapas cognitivos para o seu leitor pressuposto, guiando-o em direção aos objetos de valor do sucesso empresarial e do dinheiro (Prado, 2011). Dessa forma, a modalização do enunciatário se dá não apenas por meio de estratégias inteligíveis, mas também afetivas, com a construção de um modelo a ser emulado (o executivo que vence nos negócios e frui serviços e objetos de luxo). Como diz Prado:

No final do século 20, o capitalismo midiático tinha desenvolvido um sistema perito de elaboração de mapas cognitivos herdeiro das linhas fordistas da indústria cultural, constituindo uma efusiva e colorida corporação audiovisual - a identificação do consumidorespectador se faz, por um lado, pelo inteligível, por outro, pelas estratégias afetivas, pois se trata de propor valores para diferentes posiões de sujeito, por meio de contratos comunicacionais: a mídia mapeia valores e modaliza para os leitores modos de saber, fazer e ser, em diversas zonas temáticas, como a busca de sucesso, da beleza, do prazer, da felicidade e da riqueza (Prado, 2008, hipermídia). 
As tematizações e modalizações da crise ambiental encontradas nessas revistas visam distensionar o antagonismo entre os discursos do liberalcapitalismo e do ambientalismo. Na medida em que um discurso ambientalista se põe contra certas práticas de produção e consumo, nomeando seus adversários, os enunciadores do liberal-capitalismo não só se defendem, como também constroem visões alternativas sobre o mesmo tema. Cria-se assim um campo discursivo de embates, no qual a hegemonização do discurso é disputada (Laclau; Mouffe, 2004). Cada contendor busca suturar elementos discursivos dispersos, transformando-os em momentos articulados de seu discurso, criando assim um regime de verdade que articula posições de sujeito.

As práticas hegemônicas pressupõem um campo social atravessado por antagonismos que podem ser articulados por projetos políticos opostos. O principal objetivo dos projetos hegemônicos é construir e estabilizar os pontos nodais que formam a base de ordens sociais concretas ao articular tantos elementos disponíveis - significantes flutuantes - quanto for possível (Howarth e Stavrakakis, 2000, p.15. Tradução nossa).

Determinado discurso torna-se hegemônico (ou seja, cria um regime de verdade) pela constituição e estabilização de pontos nodais, o que caracteriza um processo em que é posto em cena um significante que anula diferenças no campo discursivo e articula redes de equivalências simbólicas. Dessa maneira, onde havia disparidade (lógicas diferenciais) passa a haver uma lógica equivalencial. 0 discurso do liberal-capitalismo tradicionalmente reconheceu o meio ambiente como simples "externalidade", o que equivale dizer, um horizonte infinito capaz de fornecer recursos e absorver dejetos (Leff, 2007, p. 75; Alier, 2009, p. 52). Na linguagem de Laclau e Mouffe, o elemento "natureza" é suturado na cadeia de equivalências do liberal-capitalismo como um momento desse discurso: um locus neutro, cuja única função é fornecer materiais e absorver dejetos (v. tb. Prates, 2013).

Nasúltimas décadas ${ }^{1}$, noentanto, os discursosambientalistas (antagonistas do discurso liberal-capitalista) empreenderam a tarefa política² de desestabilizar

1 De acordo com Enrique Leff (2007, p. 62), a "problemática ambiental" surge, nas últimas décadas do séc. 20, como uma "crise de civilização". O tema da natureza como falta na totalização de um discurso, no entanto, vem de uma mais antiga tradição de pensamento. Segundo Merleau-Ponty (2006), a partir de Hegel ela foi descrita como "impotência em obedecer ao Conceito" (Idem, p. 80. Maiúscula do autor). 2 Da maneira que a entende Chantal Mouffe em O regresso do político (1999, p. 16-17): "A ilusão do consenso e da unanimidade, bem como os apelos ao 'antipolítico', deviam ser reconhecidos como fatais para a democracia e, por isso, abandonados. [...] A democracia encontra-se em perigo não apenas 
a rede de equivalências simbólicas que sustentam o liberal-capitalismo através do deslocamento de um de seus momentos: a"natureza" passou a ser significada como limite da economia (Cechin, 2010). Os ambientalistas lograram assim expor a falta estrutural do discurso hegemônico, abrindo um campo de embates para o preenchimento do significante "natureza", agora esvaziado. De acordo com Howarth e Stavrakakis (2000, p. 13), a exposição da falta de um discurso hegemônico, estabilizado, ocorre a partir de um deslocamento significante. Para os ecologistas, por sua vez, a "natureza" (em crise) é a representação de um furo ou falta no centro do discurso liberal-capitalista. Os militantes ecologistas passaram a afirmar que a continuidade do sistema de produção e consumo levaria a uma catástrofe. Como diz Carlos Walter Porto-Gonçalves:

Do movimento ecológico parte um brado que precisa adquirir um contorno político-cultural profundo: nossa sociedade está destruindo as fontes vitais à sua própria sobrevivência. E esse brado traz em si uma das características mais especificamente humanas: a consciência da morte (Porto-Gonçalves, 2010, p. 99).

O discurso ecologista afirma: "Nos projetamos de cabeça contra um muro" (Guillaume, 2002, p. 36). Ou como diz Maffesoli (2010, p. 108): “Ele nos lembra a natureza das coisas [...], a morte como o que há de originalmente violento". De acordo ainda com Enrique Leff:

A crise ambiental expressa um questionamento sobre a natureza da natureza e do ser no mundo, com base na flecha do tempo e na entropia vistas como leis da matéria e da vida, e da morte vista como lei limite da cultura, que constitui a ordem simbólica, do poder e do saber (Leff, 2007, p. 194).

A figura da morte passa a se projetar sobre o plácido horizonte de construção de riquezas, dos hábitos de consumo e de suas miragens de gozo. Dessa maneira, a crise ambiental se instaura como ameaça a uma identidade (Laclau, 2000, p. 43) na exata medida em que busca deslocar os anteriormente celebrados objetos de valor do discurso hegemônico de consumo:

quando o consenso e a fidelidade aos valores que ela encarna são insuficientes, mas também quando a sua dinâmica combativa é travada por um aparente excesso de consenso que, normalmente, mascara uma apatia inquietante. [...] Um processo democrático saudável exige um choque vibrante de posições políticas e um conflito aberto de interesses". 


\begin{abstract}
Quando os ambientalismos expõem o furo no discurso, mostram que no centro da lógica de reprodução do capital há uma "mais explotação", uma retirada excessiva de recursos que necessariamente encontrará seu limite. A crise ambiental é um empecilho à livre fruição dos objetos de consumo. A morte espreita neste elemento desagregado das cadeias significantes, nos carros e roupas de luxo, nos projetos de infraestrutura, a negar-lhes a completude, lembrando que mesmo o mais estabilizado dos discursos deixa escapar um resto, no qual sobrevive a política entendida como antagonismo (Prates, 2013, p. 175-176).
\end{abstract}

O perigo da morte ambiental, entretanto, resulta denegado pelo discurso tecnoeficiente no coração do enunciatário que se engaja nos discursos verdes, livrando o consumidor da culpa de participar da destruição do ambiente. A estratégia passional do discurso dos enunciadores é, portanto, a da redenção pela própria promessa de fruição do consumo ambientalmente correto espécie de promessa de "mais gozar verde" proferida para um leitor pressuposto que perversamente fetichiza a própria sustentabilidade ${ }^{3}$.

Ao fazer referência aos discursos ambientalistas antagonistas, entendemo-los como consistindo duas correntes específicas do campo discursivo ambientalista4: o ecologismo profundo e o ecologismo radical. Uma terceira corrente, o ecologismo reformista, não se coloca como opositora aos objetos de valor do discurso liberal-capitalista, mas é ela exatamente que tenta a conciliação entre eles e os significados verdes. Resumidamente, o ecologismo profundo opera semioticamente para relacionar os sentidos da "natureza" às cadeias significantes da "sacralidade", da "pureza", da "beleza" da "harmonia", daquilo que chamamos de "discurso mítico-religioso". Quanto ao ecologismo radical, ele liga os sentidos do meio ambiente à tradição política de esquerda, a partir de significantes como "justiça social", "crítica" e "revolução". Por fim, como dissemos, o reformismo busca a inserção dos sentidos do meio ambiente no discurso econômico, associando-os às cadeias da "lucratividade", da "modernidade", da "competência" e da "tecnologia" (v. tb. Prates, 2013). Esta

3 Segundo Isleide Fontenelle, a revista The Economist"trabalha com a hipótese de que os consumidores devam se sentir culpados pela crise e é a partir desse contexto que o discurso da redenção aparece na referida revista" (2013, p. 8). Na revista Exame "o desdobramento da responsabilidade para culpa e redenção é ainda mais forte, embora o tom não seja de acusação ao consumidor; esse já vem construído como alguém moralmente envolvido com a causa ambiental. A culpa é apenas pressuposta, tendo em vista que é a proposta da redenção - mediante a compra de produtos de empresas ambientalmente responsáveis - que aparece como foco principal (Fontenelle, 2013, p. 9).

4 Seguindo entre outros Guillaume (2002) e Alier (2009), embora este último utilize variações sobre os termos. 
última vertente representa, do ponto de vista dos enunciadores da revista, o nó do discurso da "sustentabilidade", dada esta como mesmidade eficiente, enquanto as correntes antagonistas são postas como alteridades a serem combatidas com menos ou mais ênfase.

\section{Inversão sintomal}

A análise das revistas mostrou uma disseminação de textos nos quais as soluções tecnológicas comparecem nas tematizações sobre meio ambiente, de maneira transversal a qualquer forma de classificação. Esta situação ocorreu 48 vezes em Exame, 43 em Negócios, e 261 em Dinheiro (sendo que 80 vezes na seção de notas curtas "Sustentabilidade" da revista). Isto totaliza 352 aparições, das 629 sobre meio ambiente encontradas no corpus, ou seja, 56\% dos casos.

A inserção da solução tecnológica nas reportagens não se dá a partir de explicações complexas, mas pela materialidade da inserção de um gadget, seu suporte maquínico. Esta forma de tematização provoca um deslizamento de sentidos, que é a chave para o entendimento de como opera o discurso do ecologismo reformista. Explica-se: os enunciadores do ecologismo radical ou do ecologismo profundo afirmam que a conjunção homem-natureza, diante da atuação do sistema tecnológico se torna disjunção natureza-homem; enquanto isso, a resposta do reformismo se dá de maneira exatamente inversa: a disjunção natureza-homem, diante da atuação do sistema tecnológico, se torna conjunção homem-natureza.

Quando apontamos a importância dos gadgets, entendemos que suas significações "deslizam" sobre o furo do discurso liberal-capitalista, tamponando-o. O resultado é que o enunciador consegue lidar, por meio de uma fantasia ideológica (Žižek, 2011), com sua falta estrutural, construindo textos em que não é preciso mais escolher entre desenvolvimento capitalista e preservação do meio ambiente. Como diz Dryzek:

O desenvolvimento sustentável sempre envolve uma retórica de reafirmação. Nós podemos ter tudo isso: crescimento econômico, conservação ambiental, justiça social; e não apenas neste momento, mas perpetuamente. Nenhuma mudança dolorosa é necessária (Dryzek, 2005, p. 157. Tradução Nossa).

Žižek fala em "inversão sintomal" com base nas ambiguidades do conceito de "ideologia". Para esse autor há um tipo de "ideologia", dita "estratégica", 
caracterizada por um "conjunto de ideias" reconhecidas pelo próprio enunciador (Žižek, 1999, p. 15). Os enunciadores, nesses casos, 'sabem' da existência de alteridades, posicionando-se de modo consciente nos embates pela hegemonia do campo discursivo. Mas há outro entendimento possível do termo "ideologia", ainda de acordo com Žižek (1999, p. 15), que se trata da "ideologia 'espontânea' que atua no cerne da própria 'realidade' social". Dito de outra maneira, tratase de uma forma não-argumentativa, não-estratégica de "ideologia" (que o autor chama de seu nível zero), que consiste em "(des)apreender uma formação discursiva como fato extradiscursivo" (Žižek, 1999, p. 16).

$\mathrm{Se}$, por um lado, a sustentabilidade se manifesta como a "ideologia do complexo de ideias", confrontando-se no campo discursivo do ambientalismo com os ecologismos antagonistas (investindo em polêmicas), por outro lado uma parte considerável do corpus de análise apresenta o tema da tecnologia ecoeficiente de maneira diversa: a partir de uma série de dispositivos tecnológicos dados como soluções "autoevidentes", sendo significados de maneira "espontânea", sem que o enunciador reconheça a si mesmo como parte de um campo discursivo conflituoso.

A inversão sintomal de que fala Žižek (1999) é justamente o processo discursivo pelo qual, no lugar do furo deixado à mostra, só é possível ver como seu avesso positivado - as soluções ambientais tecnológicas apontando para um futuro verde. Justamente onde os antagonismos haviam feito visível o furo, emerge a ideologia que refaz o regime semiótico de verdade do liberalcapitalismo; ali, no ponto mais fraco da estrutura, a "sustentabilidade" constitui, erige sua força. Para escalonar o elemento disfuncional "meio ambiente" nas cadeias significantes do discurso foi preciso mais do que um mero arranjo, ou seja, foi preciso a sua instituição como momento privilegiado, seu ponto nodal (Prates, 2013).

\section{Que fazer?}

O capitalismo trouxe, portanto, para o seu campo discursivo, os argumentos de seus opositores, revertendo os significados da crítica. Aquilo que poderia limitá-lo recebe um banho ideológico-tecnológico e se transforma em seu ponto forte, o ponto forte de um capitalismo renovado em pintura verde. Isso, porém, sabem os ativistas, não transformou a matéria de ferro que subjaz sob o verde discursivizado. A questão política dessa conjuntura é que hoje não basta raspar o verde para mostrar o vermelho do ferro, porque em geral se sabe da ação da película sintomal. A ação crítica para ter eficácia tem 
de enfrentar o discurso no corpo a corpo com os dispositivos e discursos do liberal-capitalismo, ao modo dos ativistas, ou seja, não somente no campo da argumentação racional, mas também no da criação de eventos, na interposição de ações etc, deixando o antagonismo aparecer. Mas que posição a crítica deve tomar, a favor da defesa do ambiente? É isso o que discutiremos nesse final de texto, seguindo Žižek (2011), de modo a entender as dificuldades que encontra o ativista ou o interessado no entendimento das ideologias circulantes sobre $o$ ambiente dentro do capitalismo globalizado.

Como vimos na análise das revistas, há uma dominância do liberalcapitalismo como único sistema possível: "o capitalismo democrático-liberal é aceito como a fórmula da melhor sociedade possível que finalmente se encontrou - só resta torná-lo mais justo, mais tolerante, etc." (Žižek, 2011, p. 416). Daí pergunta Žižek: "endossamos essa naturalização do capitalismo ou o capitalismo global contemporâneo contém antagonismos suficientemente fortes para impedir sua reprodução indefinida?" (Žižek, 2011, p. 416). Žižek cita quatro de tais antagonismos: a ecologia, a inadequação da propriedade privada no caso da propriedade intelectual; as implicações ético-sociais dos novos avanços técnico-científicos (principalmente a biogenética); e as novas formas de apartheid, como a favelização geral do mundo.

Em função do tema deste artigo, interessa-nos principalmente a ênfase no primeiro antagonismo, a ecologia. Entretanto, veremos que há forte e inescapável interligação entre os quatro. Žižek afirma que até recentemente os atos dos sujeitos sociais eram mediados pela substância histórica, mas agora

\footnotetext{
o que assoma no horizonte é a possibilidade nunca antes vista de que uma intervenção subjetiva interferirá diretamente na substância histórica, perturbando seu curso de forma catastrófica pelo desencadeamento de uma calamidade ecológica, uma mutação biogenética funesta, um cataclismo nuclear ou sociomilitar semelhante etc (Žižek, 2011, p. 416).
}

É a famosa cena de Kubrick em que alguém aperta o botão que faz explodir a bomba nuclear no filme Dr. Strangelove. Esse é apenas um aspecto da globalização; há os outros três. Žižek propõe uma espécie de quadrado semiótico, em que aparecem as quatro características:

O princípio da 'maioria' surge como ecologia, questão que diz respeito a todos nós; a 'pobreza' caracteriza os que são excluídos e moram em favelas; a 'produção de riqueza'é, cada vez mais, algo que 
depende de avanços científicos e tecnológicos, como a biogenética; e, finalmente, a 'exploração' ressurge nos impasses da propriedade intelectual, em que o proprietário explora o resultado do trabalho coletivo. As quatro características formam um tipo de quadrado semiótico, com a intersecção de duas oposições ao longo das linhas sociedade/natureza e dentro/fora do muro social de um novo apartheid: a ecologia designa o exterior da natureza, as favelas são o exterior social, a biogenética é o interior natural e a propriedade intelectual representa o interior social (Žižek, 2011, p. 423).

O antagonismo entre os excluídos e os incluídos é o"antagonismo de nível zero, que colore todo o campo de luta". Isso posto, o que interessa politicamente são

os ecologistas que não usam a ecologia para legitimar a opressão contra os pobres "poluentes", e tentam disciplinar os países do Terceiro Mundo; só os críticos das práticas biogenéticas que resistem à ideologia conservadora (humanista-religiosa), que com tanta frequência apoia essa crítica; só os críticos da propriedade privada intelectual que não reduzem o problema a uma questão legalista (Žižek, 2011, p. 423).

Segundo Žižek, há uma diferença qualitativa entre a lacuna que separa os incluídos dos excluídos e os outros três antagonismos, que correspondem a áreas "comuns" de nosso ser social, "cuja privatização é um ato violento". São

as áreas comuns da cultura, as formas imediatamente socializadas do capital cognitivo, em primeiro lugar a linguagem, os meios de comunicação e a educação (se dessem monopólio a Bill Gates chegaríamos à situação absurda em que um indivíduo privado possuiria literalmente a textura de software de nossa rede básica de comunicação), como também a infraestrutura compartilhada de transporte público, eletricidade, correios etc; as áreas comuns da natureza externa ameaçadas pela poluição e pela exploração (do petróleo às florestas e ao próprio habitat natural); as áreas comuns da natureza interna (a herança biogenética da humanidade, que pode chegar à autoaniquilação da própria humanidade caso se dê rédeas à lógica capitalista de cercar e fechar essas áreas comuns (Žižek, 2011, p. 423).

Assim, os antagonismos não devem ser enfrentados isoladamente, mas pensados em conjunto. A crítica não deve se limitar a apontar os sintomas, pois a ideologia não pode mais ser pensada como falsa consciência; a crítica 
é um conjunto de princípios a conduzir a ação política coletiva, para preservar e construir essas áreas comuns. Nessa direção não se trata de defender uma natureza intocada como fazem os ecologistas profundos (e aqui Žižek se aproxima do ponto de vista do ecologismo radical, afastando-se da posição mítico-religiosa ao mesmo tempo em que critica o reformismo). A política deve ser pensada, portanto, a partir dos que não têm parte na partilha do social, como diria Rancière (1996), ou seja, os favelados de que fala Žižek, os homo sacer de Agamben (2002) ou os pobres de Alier. Esse antagonismo (Ranciére fala em "dano") é o ponto zero da discussão: "sem ele os outros perdem a vertente subversiva", e a ecologia se transforma em "problema do 'desenvolvimento sustentável', a propriedade intelectual em 'desafio jurídico complexo', a biogenética em questão 'ética'. Essa é, para Žižek, a única forma de construir uma discussão universal sobre tais questões antagonistas.

Grandes empresas, como a Whole Foods e a Starbucks, continuam a gozar da preferência dos liberais, muito embora se dediquem a atividades antissindicais; o truque é que vendem produtos que se pretendem atos politicamente progressistas, em si e por si. Compramos café feito de grãos comprados dos produtores a um preço justo, usamos carros híbridos, compramos empresas que oferecem bons benefícios aos funcionários (de acordo com os padrões da própria empresa) etc. A ação política e o consumo fundem-se totalmente (Žižek, 2011, p. 425).

Sem, portanto, o antagonismo de nível zero, permanece o debate e a ação na aplicação de uma maquiagem de atuações ecológicas (ou tamponamento, ou denegação). A tese central de Žižek é que o descontentamento, o mal-estar que Freud localizou na cultura, passou para a natureza. Esta não é mais "natural": "ao reduzir o homem a apenas mais um objeto natural cujas propriedades podem ser manipuladas, o que perdemos não é apenas a humanidade, mas a própria natureza" (Žižek, 2011, p. 430). Como enfrentar as ameaças da biogenética? Restringir a ciência, como sugere Habermas? Žižek afirma que não, pois isso nos impede de "enfrentar a verdadeira pergunta: como essas novas condições nos obrigam a transformar e reinventar as próprias noções de liberdade, autonomia e responsabilidade ética?" (Žižek, 2011, p. 430). A ciência e a tecnologia visam gerar novas formas de vida e não apenas dominar a natureza. A natureza não é somente um substrato intocável em que somos atirados ao nascer. 
O paradoxo é que o homem só existe na medida em que há a natureza inumana impenetrável: com a possibilidade de intervenções biogenéticas criada pelo acesso ao genoma, a espécie altera/redefine livremente a si mesma, suas próprias coordenadas (Žižek, 2011, p. 430).

A saída desse panorama não é apostar na ecologia do medo, pois ela pode vir a se tornar uma espécie de religião, "a de ter uma autoridade inquestionável capaz de impor limites" (Žižek, 2011, p.434), a partir do argumento de que somos seres finitos ${ }^{5}$. O mundo como um Todo orgânico é uma ideia reguladora, no sentido de Kant. A proposta de Žižek é partirmos não da ideia de uma natureza ordenada e equilibrada: "e se a verdadeira posição materialista começar com a aceitação do Em-si como multiplicidade caótica e sem sentido?" (Žižek, 2011, p. 439). Para ele, precisamos de uma ecologia sem natureza: essa noção de natureza como algo em que confiamos, equilibrado e regulado, que nos desperta uma relação de confiança e fé é o próprio obstáculo "que nos impede de enfrentar a crise ecológica em seu aspecto mais radical" (Žižek, 2011, p. 440).

A ecologia do medo oculta uma dimensão de terror. Que dimensão é essa? Nós temos a experiência da cultura como segunda natureza, espécie de habitat simbólico, como se fossemos raízes de planta simbólica, raízes fincadas no mundo da vida (Lebenswelt). O desafio da tecnologia está, segundo Žižek, em incitar a "nos isolar dessa inserção (no mundo da vida) e aceitar o vazio radical da existência. Esse é o terror que nem Heidegger ousou enfrentar" (Žižek, 2011, p. 446). Diz Žižek:

O nosso mundo da vida simbólico, no qual estamos sempre-já inseridos de forma préreflexiva, não são nossas entranhas simbólicas, as quais exteriorizamos? E o verdadeiro desafio da tecnologia não é repetirmos a passagem da planta para animal, cortando simbolicamente as raízes e aceitando o abismo da liberdade?" (Žižek, 2011, p.447).

O capitalismo não tem um espírito objetivo, um sujeito coletivo que opera como uma imposição externa, que destrói o planeta. O grande problema para Žižek está em que, embora nossos atos possam produzir catástrofes, continuamos a perceber essas consequências como anônimas ou sistêmicas:

5 Outro autor que combate essa poesia da finitude é Badiou (1996). 
E aqui voltamos à lógica do louco que sabe que não é um grão de milho, mas teme que as galinhas não tenham se dado conta disso sabemos que somos responsáveis, mas a galinha (o grande Outro) ainda não percebeu isso. Ou, na medida em que o conhecimento é a função do eu, e a crença é a função do Outro, conhecemos muito bem o real estado de coisas, mas não acreditamos - o grande Outro nos impede de acreditar, de assumir esse conhecimento e essa responsabilidade" (Žižek, 2011, p.449).

É preciso atuar a partir das conjunções ideológicas que circundam a noção de natureza e do modo pelo qual as vivemos. Não podemos, conforme Žižek, confiar no discurso científico que quer fazer avaliação objetiva dos riscos, nem no senso comum, que não aceita que uma verdadeira catástrofe possa ocorrer (o filme do Kubrick Dr. Strangelove mostra esse impensável). Para parar o trem do capitalismo de crescimento infinito não basta criticar a noção padrão de progresso histórico linear, mas é preciso que nos livremos "dessa noção 'histórica' de temporalidade: temos de criar uma nova noção do tempo" (Žižek, 2011, p. 453). Como diz Boaventura Santos:

Prolepse é uma figura literária bastante encontrada em romances, nos quais o narrador sugere claramente a ideia de que conhece bem o fim mas não vai contá-lo. É conhecer no presente a história futura. Nossa razão ocidental é muito proléptica, no sentido de que já sabemos qual é o futuro: o progresso, o desenvolvimento do que temos. É mais crescimento econômico, é um tempo ideal linear que de alguma maneira permite uma coisa espantosa: o futuro é infinito. [...] O que vou lhes propor é uma estratégia oposta: expandir o presente e contrair o futuro. Ampliar o presente para incluir nele muito mais experiência, e contrair o futuro para prepará-lo (Santos, 2011, p. 26).

\section{Referências}

AGAMBEN, Giorgio. Homo sacer. Belo Horizonte: UFMG, 2002.

ALIER, Juan Martínez. O Ecologismo dos pobres: conflitos ambientais e linguagens de valoração. São Paulo: Contexto, 2009.

BADIOU, Alain. O ser e o evento. RJ, Jorge Zahar/UFRJ: 1996.

CECHIN, Andrei. A natureza como limite da economia: a contribuição de Nicholas Georgescu-Roegen. São Paulo: Senac; Edusp, 2010. 
DRYZEK, John. The Politics of the Earth: environmental discourses. Segunda edição. Nova lorque: Oxford University Press, 2005.

FONTENELLE, Isleide. A resignificação da crise ambiental pela mídia de negócios: responsabilidade empresarial e redenção pelo consumo. Revista Galáxia V.13. N26, SP: Educ, 2013.

FOUCAULT, Michel. O nascimento da biopolítica. São Paulo, Martins Fontes: 2008.

GUILLAUME, Marc. Virus vert: entretiens avec Isabelle Bourboulon. Paris: Descartes \& Cie, 2002.

HOWARTH, David; STAVRAKAKIS, Yannis. Introducing discourse theory and political analysis. In: HOWARTH, David; NORVAL, Alleta; STAVRAKAKIS, Yannis. Discourse Theory and Political Analysis: identities, hegemonies and social change. Nova lorque: Manchester U.P., 2000.

LACLAU, Ernesto. Nuevas reflexiones sobre la revolución de nuestro tiempo. Buenos Aires: Nueva visión, 2000.

LACLAU, Ernesto; MOUFFE, Chantal. Hegemonía y estrategia socialista: hacia una radicalización de la democracia. Segunda edição. Buenos Aires: Fondo de Cultura Económica, 2004.

LEFF, Enrique. Epistemologia ambiental: Quarta edição revista. São Paulo: Cortez, 2007.

MAFFESOLI, Michel. Saturação. São Paulo: Iluminuras, 2010.

MERLEAU-PONTY, Maurice. A natureza. São Paulo: Martins Fontes, 2006.

MOUFFE, Chantal. $O$ regresso do político. Lisboa: Gradiva, 1999.

PORTO-GONÇALVES, Carlos W. Os (des)caminhos do meio ambiente. São Paulo: Contexto, 2010.

PRADO, José L.A. et al. A invenção do Mesmo e do Outro na mídia semanal. DVD Hipermídia. São Paulo: PUC-SP, 2008.

Regime de visibilidade em revistas. DVD Hipermídia. São Paulo: PUC-SP, 2011.

PRATES, Vinicius. A natureza deslocada: construção dos sentidos da sustentabilidade nas revistas de economia e negócios Exame, Época Negócios e IstoÉ Dinheiro. 220f. Tese (Doutorado em Comunicação e Semiótica) - Programa de Estudos Pós-graduados em Comunicação e Semiótica, PUC-SP, São Paulo,2013.

RANCIÈRE, Jacques. O desentendimento. São Paulo: Editora 34, 1996. 
SANTOS, Boaventura Sousa. Reinventar a teoria crítica. São Paulo: Boitempo, 2011.

ŽIŽEK, Slavoj. Em defesa das causas perdidas. São Paulo: Boitempo, 2011.

Como Marx inventou o sintoma? In: Um mapa da ideologia. ŽIŽEK, Slavoj et al. Rio de Janeiro: Contraponto, 1999.

Recebido em 05 de maio de 2015

Aceito em 19 de maio de 2015.

Endereço dos Autores:

José Luiz Aidar Prado <aidarprado@gmail.com>

PUC/SP - Rua Ministro Godoi, 969, São Paulo SP - 4 andar - sala 4 A8

Vinicius Prates < viniciusprates.vp@gmail.com>

Universidade Presbiteriana Mackenzie

Rua da Consolação, 930 - Consolação, São Paulo - SP, 01302-907 